\title{
Potential Outer Membrane Protein Candidates for Vaccine Development Against the Pathogen Vibrio anguillarum: A Reverse Vaccinology Based Identification
}

\author{
Pallavi Baliga $^{1} \cdot$ Malathi Shekar $^{1} \cdot$ Moleyur Nagarajappa Venugopal $^{1}$
}

Received: 19 June 2017 / Accepted: 31 October 2017 / Published online: 8 November 2017

(C) Springer Science+Business Media, LLC 2017

\begin{abstract}
Reverse vaccinology is a widely used approach that has facilitated the rapid identification of vaccine candidates suitable in vaccine development for pathogens. Vibrio anguillarum is a major pathogen responsible for vibriosis in fish and shellfish leading to huge economic losses to the aquaculture industry. Although commercial vaccines are available for fish against this bacterium they have their own limitations. In this study, we used the reverse vaccinology strategy to screen and identify $V$. anguillarum outer membrane proteins (OMPs) that could serve as vaccine candidates. Our analysis identified 23 antigenic outer membrane proteins which were highly conserved ( $>98 \%$ identity) across serovars of this bacterium. Of the 23 , two were identified as outer membrane lipoproteins. Among the OMPs identified 18 were novel to this study and conserved across several Vibrio spp. with an identity of 21-93\%. While the least ( $>48 \%$ ) identity was observed for $V$. anguillarum ferrichrome-iron transporter protein, the highest identity $(>80 \%)$ was seen for outer membrane proteins OmpK, BamA, OmpU, Fatty acid transporter, and two hypothetical proteins. These potential vaccine targets identified could contribute to the development of effective vaccine not only against $V$. anguillarum but also across other Vibrio spp. In addition, several B-cell and T-cell epitopes were predicted for the novel OMPs in this study which could aid in narrowing
\end{abstract}

Electronic supplementary material The online version of this article (https://doi.org/10.1007/s00284-017-1390-z) contains supplementary material, which is available to authorized users.

Malathi Shekar

malathishekar@rediffmail.com

1 Department of Fisheries Microbiology, College of Fisheries, Karnataka Veterinary, Animal and Fisheries Sciences University, Mangalore 575 002, India down peptide selection in designing a suitable epitope-based vaccine.

Keywords Vibrio anguillarum - Outer membrane proteins $\cdot$ Reverse vaccinology $\cdot$ Vaccine candidates . Epitopes $\cdot$ MHC class proteins

\section{Introduction}

Vibrio anguillarum (Listonella anguillarum), an important pathogen of the genus Vibrio is the leading cause of the disease 'vibriosis' in commercially important fish and shellfish culture [2, 24, 29]. Vibriosis, a fatal hemorrhagic septicaemic disease, is known to infect $>50$ species of fish and considered as a major economical threat to marine and freshwater aquaculture industry worldwide [14]. In aquaculture practice, control of vibriosis is mainly through the use of antibiotics. However, the rising incidence of resistance to commonly used antibiotics and also the transfer of resistance to other bacterial strains is considered as a major limitation and a global concern [30].

There is an increasing need for alternatives to antibiotics such as vaccines to control disease in aquaculture. However, the development of new vaccines depends on the identification of new potential vaccine antigens. In recent years, the availability of complete bacterial genomic sequences and various in silico tools has accelerated the identification of bacterial antigens through a computer-based approach called 'Reverse vaccinology' (RV). It involves the screening of the genome protein-coding sequences for antigenic proteins capable of eliciting an immune response in host organism [36]. The RV technique was first applied to design a vaccine against the serogroup B Neisseria meningitides [34]. Ever since, the technology has been successfully applied to 
several bacterial and viral pathogens such as Acinetobacter baumannii [7], Bacillus anthracis [1], Campylobacter [28], Cryptosporidium hominis [27], Mycobacterium tuberculosis [4], Streptococcus pneumoniae [45], and Herpes simplex virus [46].

In the RV approach for Gram-negative bacteria, special attention has been given to the exported outer membrane proteins (OMPs) due to their role in host-pathogen interaction. Approximately $2-3 \%$ of the genes encode for OMPs in Gram-negative bacteria [22] which are essential for maintaining the integrity and in the selective permeability of molecules across membranes [5]. In addition, few OMPs act as adhesins and take part in the pathogenicity of the bacterium. Furthermore, due to their surface localization, they are exposed targets to the host immune system [8] making them therefore ideal vaccine candidates.

Experimental evidence through work carried out by several researchers reveals specific Gram-negative bacterial OMPs to be useful as potent immunogenic molecules providing significant protection to fish when challenged with pathogenic bacteria $[13,21,26,35,43]$. Currently available commercial vaccines for $V$. anguillarum are inactivated products of the bacterium which do not provide cross protection to the several existing serotypes of this pathogen, thus limiting its use [41]. In V. anguillarum, exploiting OMPs as protective antigens against disease caused by the pathogen is very limited. Thus in this study, we identified novel outer membrane proteins using the RV strategy, candidates which could act as a potential source for the development of an effective vaccine against the pathogen $V$. anguillarum. We also report here OMPs conserved across Vibrio species which could be exploited as targets to develop a crossprotective vaccine capable of inciting protective immunity against pathogenic vibrios.

\section{Materials and Methods}

\section{Sequence Retrieval and Identification of Antigenic Outer Membrane Proteins}

The complete nucleotide (accession numbers CP002284.1 and CP002285) sequences of the $\mathrm{O} 1$ serotype $V$. anguillarum 775 strain were downloaded from the National Centre for Biotechnology Information (https://www.ncbi.nlm.nih. gov/) database. A total of 3867 protein sequences encoded by the two chromosomes were extracted in FASTA format for further analysis. In the RV approach, a protein vaccine candidate is identified based on defined desirable attributes such as protein subcellular localization, topology, adhesin/ antigenicity probability, epitopes, and its binding to the major histocompatibility complex (MHC) class I and II molecules [46]. In this study, predicted protein sequences were analyzed for the presence of signal peptides using Signal P 4.1 server (http://www.cbs.dtu.dk/services/SignalP/) [33]. Prediction of transmembrane segments and the twodimensional topology of OMPs were determined using the online server PRED-TMBB (http://bioinformatics.biol.uoa. gr/PRED-TMBB/) [3]. Lipoproteins in the outer membrane and their subcellular localization were predicted using LipoP 1.0 [20] and PSORTb ver. 3.0.2 [47] servers, respectively. The proteins identified as OMPs were evaluated for their adhesin and antigenicity probability. The Seapath ver. 1.0 program (CSIR-IGIB-Jalaja Technologies, Bangalore, India) was used to predict the adhesin probability of the protein. The Seapath program has an optimal sensitivity of $89 \%$ and specificity of $100 \%$ and can identify $97.4 \%$ of adhesins in a wide range of bacteria [9]. The probability of being an adhesin has a default cut-off of $\geq 0.7$. Probability values $>0.6$ and $<0.7$ were considered as "twilight zone" for adhesin-like characteristics. The antigenicity of proteins was predicted using two different softwares: Vaxign (http://www.violinet.org/vaxign/) [17] and VaxiJen v2.0 (http://www.jenner. ac.uk/VaxiJen) [10]. Vaxign and VaxiJen programs have sensitivity and specificity corresponding values 0.494 and 0.853 and 0.554 and 0.909 , respectively [19]. A threshold cut-off of 0.5 was used in both programs. The molecular weight of the OMPs was determined using the Sequence manipulation suite [42]. The EMBOSS tool 'Antigenic' (http://bioinfo.nhri.org.tw/gui/) [23,31] was used in identifying the potential antigenic peptides in shortlisted outer membrane proteins. Minimum length of antigenic residues was set to 6 and minimum score to 1 . The BLASTp program (https:// blast.ncbi.nlm.nih.gov/Blastp) was used to find the conservation of identified OMPs among $V$. anguillarum serovars as well as those present in other Vibrio spp.

The antigenic OMPs in this study were subjected to the identification of B-cell and T-cell epitopes. Linear B-cell epitopes were predicted using the BCPreds server (http:// ailab.ist.psu.edu/bcpred/predict.html). The server provides three methods based on different algorithms: BCPred and AAP (amino acid antigenicity) which is a fixed length epitope prediction method $[6,11]$ and FBCPred a flexible length prediction method [12]. In this study, B-cell epitopes were predicted using all three methods with epitope length as 12 and a specificity of $75 \%$. Non-overlapping epitopes predicted by the three prediction methods were combined to derive at a consensus B-cell epitope sequence.

To identify T-cell epitopes Vaxitop, an internally developed program of Vaxign server that relies on statistical $P$ value as the cut-off was used. To predict T-cell epitopes, the default $P$ value of 0.05 was selected as it provides a high and balanced sensitivity and specificity [17]. Fish MHC sequences were retrieved from the IPD-MHC FISH database (https://www.ebi.ac.uk/ipd/mhc/group/FISH). 


\section{Results and Discussion}

\section{Prediction of Antigenic Outer Membrane Proteins}

In this study, screening of the 3867 proteins encoded by $V$. anguillarum 775 revealed 265 to have a signal peptide sequence ( 16-41 amino acids in length) in the N-terminal region. In Gram-negative bacteria, signal peptides play a key role in transport and subcellular localization of proteins to the inner membrane, the periplasm, the outer membrane, or to the extracellular environment [40]. Proteins localized in the outer membrane have a characteristic $\beta$-strand secondary structure that traverses the lipid layer in an anti-parallel manner to form a barrel-shaped structure. A Pred-TMBB analysis for the 265 proteins positive for the signal sequence, showed 90 proteins to form $\beta$-barrel proteins of which only 38 proteins were analyzed to be localized in the outer membrane. Proteins showing localization in regions other than the outer membrane were omitted and not subjected to further analysis. The predicted $V$. anguillarum OMPs, their residue numbers, molecular weight total transmembrane segments, and exposed antigenic peptides are provided in Table S1.

Outer membrane proteins that function as adhesins are preferred vaccine targets. The adhesin probability for the 38 OMPs ranged from 0.11 to 0.89 . Among these, 23 OMPs (13 with probability values $\geq 0.7$ and 10 showing values in the "twilight zone") were selected as adhesin proteins (Table 1).

Table 1 List of potential $V$. anguillarum vaccine candidates

\begin{tabular}{|c|c|c|c|c|c|c|c|c|}
\hline \multirow[t]{2}{*}{ Protein accession } & \multirow[t]{2}{*}{ Protein description } & \multirow{2}{*}{$\begin{array}{l}\text { Length } \\
(\text { amino } \\
\left.\text { acids }^{\#}\right)\end{array}$} & \multirow[t]{2}{*}{ Mol. wt. (kDa) } & \multirow{2}{*}{$\begin{array}{l}\text { No. of } \\
\text { TMs pre- } \\
\text { dicted }\end{array}$} & \multirow{2}{*}{$\begin{array}{l}\text { No. of exposed } \\
\text { antigenic pep- } \\
\text { tides }\end{array}$} & \multirow{2}{*}{$\begin{array}{l}\text { Adhesin } \\
\text { probabil- } \\
\text { ity }\end{array}$} & \multicolumn{2}{|c|}{$\begin{array}{l}\text { Antigenicity } \\
\text { score }\end{array}$} \\
\hline & & & & & & & VaxiJen & Vaxign \\
\hline AEH31724 $4^{\mathrm{a}}$ & Hypothetical OMP & 324 & 35.9 & 4 & 17 & 0.79 & 0.54 & 0.59 \\
\hline AEH31940 & $\begin{array}{l}\text { Ferrichrome-iron transporter } \\
\text { OMP }\end{array}$ & 664 & 73.9 & 22 & 12 & 0.66 & 0.64 & 0.52 \\
\hline AEH32461 & OmpK-nucleoside-specific OMP & 243 & 27.4 & 12 & 2 & 0.67 & 0.67 & 0.54 \\
\hline AEH32514 & $\begin{array}{l}\text { BamA/YaeT-outer membrane } \\
\text { assembly factor protein }\end{array}$ & 790 & 88.6 & 26 & 12 & 0.64 & 0.56 & 0.50 \\
\hline $\mathrm{AEH} 32572^{\mathrm{a}}$ & $\begin{array}{l}\text { LolB-outer membrane lipopro- } \\
\text { tein }\end{array}$ & 191 & 21.4 & 4 & 7 & 0.68 & 0.67 & 0.55 \\
\hline AEH32793 & OmpV-OMP & 238 & 26.3 & 10 & 6 & 0.86 & 0.55 & 0.68 \\
\hline AEH32871 & Hypothetical OMP & 310 & 34.0 & 14 & 5 & 0.81 & 0.51 & 0.63 \\
\hline AEH32884 & Hypothetical OMP & 310 & 33.3 & 14 & 5 & 0.84 & 0.74 & 0.65 \\
\hline AEH33067 & $\begin{array}{l}\text { Periplasmic amino acid binding } \\
\text { OMP }\end{array}$ & 223 & 24.5 & 8 & 3 & 0.66 & 0.52 & 0.58 \\
\hline AEH33077 & $\begin{array}{l}\text { TonB-dependent iron transport } \\
\text { OMP }\end{array}$ & 695 & 76.8 & 22 & 9 & 0.61 & 0.68 & 0.53 \\
\hline AEH33152 & Hypothetical OMP & 141 & 15.0 & 6 & 2 & 0.72 & 0.89 & 0.52 \\
\hline AEH33621 & Fatty acid transport OMP & 398 & 43.2 & 14 & 9 & 0.80 & 0.59 & 0.62 \\
\hline AEH33622 & Fatty acid transport OMP & 399 & 43.3 & 14 & 6 & 0.89 & 0.59 & 0.70 \\
\hline AEH33699 & Outer membrane porin protein & 347 & 37.9 & 16 & 3 & 0.71 & 0.80 & 0.54 \\
\hline AEH33731 & $\begin{array}{l}\text { TetR-transcriptional regulator } \\
\text { OMP }\end{array}$ & 372 & 42.4 & 16 & 3 & 0.63 & 0.75 & 0.64 \\
\hline AEH34033 & OmpU-OMP & 309 & 33.4 & 14 & 4 & 0.62 & 0.81 & 0.50 \\
\hline AEH34348 & Hypothetical OMP & 235 & 26.6 & 12 & 5 & 0.64 & 0.82 & 0.52 \\
\hline AEH34505 & Hypothetical OMP & 167 & 18.3 & 6 & 3 & 0.62 & 0.75 & 0.51 \\
\hline AEH34566 & TraF-conjugal transfer OMP & 361 & 39.1 & 11 & 6 & 0.78 & 0.75 & 0.60 \\
\hline AEH34817 & LamB-OMP & 388 & 42.7 & 16 & 7 & 0.78 & 0.57 & 0.61 \\
\hline AEH35019 & Hypothetical OMP & 402 & 43.8 & 18 & 5 & 0.71 & 0.78 & 0.55 \\
\hline AEH35061 & $\begin{array}{l}\text { Long-chain fatty acid transport } \\
\text { OMP }\end{array}$ & 390 & 44.6 & 12 & 9 & 0.80 & 0.58 & 0.72 \\
\hline AEH35196 & Cyclodextrin-specific OMP & 322 & 37.3 & 14 & 2 & 0.74 & 0.56 & 0.54 \\
\hline
\end{tabular}

$O M P$ outer membrane proteins, TMs transmembrane regions

\#Amino acids in proteins minus signal peptide

${ }^{\text {a }}$ Predicted lipoproteins 
The VaxiJen and Vaxign servers identified 37 and 27 OMPs, respectively, to be antigenic having antigenicity probability scores $>0.5$ (Table S1). Based on the results of Seapath, VaxiJen, and Vaxign analysis, 23 OMPs that met the criteria of being an adhesin and having a threshold antigenic score $>0.5$ in both Vaxign and VaxiJen prediction were shortlisted as potential vaccine candidates. Table 1 lists the final selection of potential vaccine candidates together with their length, molecular weight, predicted transmembrane helices, exposed antigenic peptides predicted, adhesin, and antigenicity probability scores. Among the 23 outer membrane proteins two (AEH31724 and AEH32572) were identified as lipoproteins by the LipoP 1.0 server (Table 1 ). AEH31724 is a hypothetical OMP with 324 amino acids, while AEH32572 having a length of 191 amino acids has been annotated as LolB OMP. The $\beta$-transmembranes predicted for the two lipoproteins were 4 (Table 1). The lipoproteins were also predicted to be adhesins and antigenic. This suggests that the two lipoproteins are possible protective antigens worth experimental evaluation.

A literature search, for experimental work for the $21 \mathrm{~V}$. anguillarum OMPs identified in this study, revealed only three OMPs (OmpK, OmpU, and LamB) to have been studied for their potential immunogenicity in fish. The Indian major carp Labeo rohita on vaccination with recombinant OmpK was reported to be well protected when challenged with $V$. anguillarum [16]. Similarly, vaccination with recombinant LamB protein showed cross protection in zebra fish injected with heterogenous Vibrio species [25]. V. anguillarum OmpU was shown to play a role in bile resistance and biofilm formation, considered important for bacterial survival and colonization in the fish gut [44].

To date, more than 20 serovars exist for $V$. anguillarum. Therefore, the identified OMPs in V. anguillarum 775 were also studied for their conservation across different serovars. A Pan-genome analysis of the shortlisted OMPs (Table 1), against $V$. anguillarum genomes available for 28 different serovars in the NCBI database, showed all OMPs to be highly conserved ( $>98 \%$ ) across serovars isolated from different geographic locations (data not shown). In contrast, orthologous clustering of the identified outer membrane proteins across Vibrio spp. (V. alginolyticus; V. campbellii; $V$. cholerae; V. fischeri; V. fluvialis; V. furnissii; V. harveyi; $V$. mimicus; V. owensii; V. parahaemolyticus; V. splendi$d u s$, and $V$. vulnificus) revealed several of these proteins to be common with similarities ranging from 21 to $93 \%$ (Table S2). As seen from the table, at a $50 \%$ cut-off value, $90.5 \%$ of $V$. anguillarum OMPs were found to be highly conserved in $V$. cholerae. Among the outer membrane proteins, the Ferrichrome-iron transporter OMP (AEH31940), although conserved was seen to have a low identity $(<48 \%)$ across Vibrio spp. and hence considered unique to $V$. anguillarum. Except in $V$. cholerae similar low conservation was also seen for the OMP porin protein (AEH33699). In contrast, few $V$. anguillarum outer membrane proteins considered immunogenic (Table 1) showed high conservation across different vibrios which included OMPs, OmpK (AEH32461), BamA/YaeT (AEH32541), Fatty acid transporters (AEH33621 and AEH33622), OmpU (AEH34033), and two hypothetical proteins (AEH33152 and AEH34348). While the protective efficacy of proteins OmpK and OmpU has already been established [16, 44], the remaining could be considered as novel vaccine candidates for which in vivo experiments could be performed to validate the immune and protective power of these antigens not only against disease caused by $V$. anguillarum but also against the disease caused by other vibrios.

\section{Prediction of B-cell and T-cell Epitopes for Antigenic OMPs}

Identification of epitopes in target antigens is one of the key steps in designing an epitope-based sub-unit vaccine. For an antigen to be considered ideal it should be capable of eliciting a humoral immune and cellular response by triggering the B-cells and T-cell selectively. Thus, an in silico approach was used to identify antigenic B-cell and T-cell epitopes present in the potential $V$. anguillarum OMPs identified as vaccine candidates in this study.

\section{B-cell Epitope Identification}

The cell surface B-cell epitopes of pathogens are antigenic determinants that interact with antibodies secreted by the B lymphocytes, eliciting a humoral immune response. Prediction of B-cell epitopes using the three predictors supported by the BCPred server identified several linear B-cell epitopes of length 12-15 (Table 2) for the antigenic OMPs identified in this study. Table 2 summarizes the number of B-cell epitope predicted for each OMP and their length. As seen from Table 2, the B-cell prediction methods failed to identify antibody binding epitopes in two of the OMPs, i.e., Fatty acid transport OMP (AEH33621) and long-chain fatty acid OMP (AEH35061). The B-cell peptides predicted for the remaining OMPs ranged from 1 to 7 . The residue lengths for B-cell peptides in this study ranged from 12 to 15 , which is in accordance to the experimental proven B-cell epitope length required to stimulate the immune cell to produce antibodies that bind the peptide [11]. B-cell epitopes representing bacterial OMP peptides have been used in the development of antimicrobial vaccines [18, 39]. Thus, the identified B-cell peptides of antigenic $V$. anguillarum OMPs could serve as a guide in assessing the B-cell-induced protective antibody response in vaccinated animals as well as in B-cell peptide vaccine design. 
Table 2 Predicted B-cell epitopes for $V$. anguillarum outer membrane proteins

\begin{tabular}{|c|c|c|c|c|}
\hline Protein accession & Antigen & $\begin{array}{l}\text { Amino acid start } \\
\text { position }\end{array}$ & Epitope & Epitope length \\
\hline \multirow[t]{3}{*}{ AEH31940 } & \multirow[t]{3}{*}{ Ferrichrome-iron transporter OMP } & 243 & FGEPDHDDFDKTQ & 13 \\
\hline & & 287 & SSAYQNAWQDSDPYT & 15 \\
\hline & & 365 & NPTYGNVPDLSS & 12 \\
\hline \multirow[t]{2}{*}{ AEH32461 } & \multirow[t]{2}{*}{ OmpK-nucleoside-specific OMP } & 59 & LSNPSSDKEGKEK & 13 \\
\hline & & 179 & GMDDKNTALKTSNG & 14 \\
\hline \multirow[t]{6}{*}{ AEH32514 } & \multirow{6}{*}{$\begin{array}{l}\text { BamA/Yae T-outer membrane assembly } \\
\text { factor protein }\end{array}$} & 566 & AGNHQRAFYKMTV & 13 \\
\hline & & 617 & GYGKTDGNDNLF & 12 \\
\hline & & 633 & NYYAGGFTTLRGFG & 14 \\
\hline & & 659 & ATGCNGNNGGNNR & 13 \\
\hline & & 674 & SATDDSVGGNAV & 12 \\
\hline & & 719 & WDTEFDYKDGKL & 12 \\
\hline \multirow[t]{3}{*}{ AEH32793 } & \multirow[t]{3}{*}{ Outer membrane protein } & 22 & GAFGSTDLLKDQ & 12 \\
\hline & & 162 & NYYFGVKDKEAT & 12 \\
\hline & & 213 & SSDVANSPIVES & 12 \\
\hline \multirow[t]{2}{*}{ AEH32871 } & \multirow[t]{2}{*}{ Hypothetical OMP } & 126 & SITKSDEPNGWA & 12 \\
\hline & & 285 & TANTPEYKEDKN & 12 \\
\hline \multirow[t]{2}{*}{ AEH32884 } & \multirow[t]{2}{*}{ Hypothetical OMP } & 63 & TDESKESPYEGA & 12 \\
\hline & & 288 & IENGDAGKDQEE & 12 \\
\hline \multirow[t]{2}{*}{ AEH33067 } & \multirow[t]{2}{*}{ Periplasmic amino acid binding OMP } & 127 & NKPDANDLTTNL & 12 \\
\hline & & 186 & SGKANPNAQKYID & 13 \\
\hline \multirow[t]{7}{*}{ AEH33077 } & \multirow[t]{7}{*}{ TonB-dependent iron transport OMP } & 176 & NKTDSDIAHSSYK & 13 \\
\hline & & 188 & GQEQQNFADRKE & 12 \\
\hline & & 301 & GRPPYTPANADNQ & 13 \\
\hline & & 356 & SNTNTELNSDPA & 12 \\
\hline & & 369 & PNQVLVYTPDAT & 12 \\
\hline & & 412 & TDPGGSTTEPLV & 12 \\
\hline & & 663 & EYYRWNDIRGKT & 12 \\
\hline AEH33152 & Hypothetical OMP & 120 & MNYTLGDDDIGT & 12 \\
\hline AEH33621 & Fatty acid transport OMP & - & - & - \\
\hline \multirow[t]{3}{*}{ AEH33622 } & \multirow[t]{3}{*}{ Fatty acid transport OMP } & 160 & PAQTKPLPQGTT & 12 \\
\hline & & 219 & KESGKVVNDTGS & 12 \\
\hline & & 363 & ESRGYASDDAAQ & 12 \\
\hline AEH33699 & Outer membrane porin protein & 321 & TPADGDGKGNAD & 12 \\
\hline \multirow[t]{3}{*}{ AEH33731 } & \multirow[t]{3}{*}{ TetR-Transcriptional regulator OMP } & 109 & EQRGDNDTTLNLS & 13 \\
\hline & & 155 & DYKNNQNITQYQ & 12 \\
\hline & & 199 & SDIAPGSTLKDST & 13 \\
\hline \multirow[t]{4}{*}{ AEH34033 } & \multirow[t]{4}{*}{ OmpU-OMP } & 62 & DEGTADNKGDLD & 12 \\
\hline & & 149 & QESTSAITDNNA & 12 \\
\hline & & 217 & QDKAASKTDKTG & 12 \\
\hline & & 288 & DSDKVGKAKSED & 12 \\
\hline AEH34348 & Hypothetical OMP & 60 & LDKNGKENKRQA & 12 \\
\hline AEH34505 & Hypothetical OMP & 81 & SQATFTSTQVVD & 12 \\
\hline \multirow[t]{2}{*}{ AEH34566 } & \multirow[t]{2}{*}{ TraF-conjugal transfer OMP } & 206 & ADYDKSETNDNA & 12 \\
\hline & & 324 & AVTFGIGISPGD & 12 \\
\hline
\end{tabular}


Table 2 (continued)

\begin{tabular}{lllll}
\hline Protein accession & Antigen & $\begin{array}{l}\text { Amino acid start } \\
\text { position }\end{array}$ & Epitope & Epitope length \\
\hline AEH34817 & LamB-OMP & 58 & NSTGRLGNEGNG & 12 \\
& & 98 & EVGVPKAYAGGT & 12 \\
& & 144 & GQGGGFYNLNLG & 12 \\
& & 165 & SATGASPSDHPDG & 12 \\
& & 205 & DDNSDPTAKKLN & 12 \\
AEH35019 & Hypothetical OMP & 279 & EDGAYKQYDRTN & 12 \\
& & 30 & TEFGKPDYKTAG & EQANKDSKSDDG \\
AEH35061 & & 203 & NFGGWSGGDDKQ & - \\
AEH35196 & Long-chain fatty acid OMP & 249 & - & GDNETNNASNSG \\
& Cyclodextrin-specific OMP & 242 & LAGWEAKNESEL & 12 \\
\hline
\end{tabular}

\section{T-cell Epitopes Identification}

In vertebrates, the major histocompatibility complex (MHC) genes play an essential role in activating the adaptive immune response. The cell surface proteins encoded by the MHC genes bind peptide fragments derived from pathogens and present them to T-cells that activate a specific immune response. Therefore the prerequisite in vaccine development is the identification of T-cell epitopic regions within antigenic proteins which can recognize and bind to the MHCs [32]. At present, several in silico tools are available to predict epitope sequences for a protein. However, they are mainly trained to predict peptides based on binding to human and lower mammalian MHC alleles and not for fish MHC alleles. Therefore as a first step, we downloaded the MHC sequences available for salmonid fish in the IPD-MHC FISH database. Earlier studies have shown that MHC class I and class II are present in teleosts, many of which share genes that are evolutionarily related to the classical human MHC genes [15, 38]. A BLAST analysis in this study showed that among the several human MHC alleles, the fish MHC sequences had the closest identity ( 35-38\%) to human HLA-A (MHC class I) and HLA-DP and HLA-DQ (MHC class II) sequences. Hence prediction of T-cell epitopes for each antigenic OMP predicted in this study was performed using the Vaxitop program set against human MHC HLA-A2, HLA DPA1/DPB1, HLA DQA1/ DQB1, and HLA DRA1/DRB1 alleles.

The Vaxitop analysis identified T-cell peptide fragments for antigenic OMPs in this which ranged from 1 to 8 (Table 3). Among OMPs, the predicted T-cell epitopes was highest for BamA (AEH32514) followed by LamB (AEH34817) with 8 and 7 peptides, respectively. The peptide length ranged from 9 to 20 residues and corresponded to exposed regions of the OMPs. The peptides binding to
MHC class I and class II were seen to differ in their length. In peptides showing binding to class I and class II alleles, the MHC class I epitopes were observed to be shorter (underlined in Table 3) in comparison to the same peptide binding to MHC class II alleles. Overlapping peptides that correspond to the antigenic outer membrane proteins and their binding probabilities are presented in Table 3. Our study showed that none of the peptide fragments recognized the MHC class II allele HLA-DRA1/DRB1 (data not shown). As seen from Table 3, the peptides predicted had a greater binding frequency to HLA-A2 (MHC class 1) followed by HLA-DQ (MHC class II) and HLA-DP alleles. It was also observed that the peptides corresponding to the TetR-transcriptional regulator OMP (AEH33731), hypothetical OMP (AEH34505), and cyclodextrin-specific OMP had binding affinity only to MHC class II alleles and not to the MHC class I allele. In contrast, in few antigenic outer membrane proteins some of the peptide fragments were seen to recognize and bind to both the MHC class I and class II alleles (Table 3) which could be chosen for further narrowing down on epitope candidates during vaccine design. Further, among $V$. anguillarum OMPs, the Ferrichrome-iron transporter protein (AEH31940) exhibited low homology to same protein in other Vibrio spp. (Table S2). Hence, the immunodominant epitopes predicted for this protein could be exploited in designing an exclusive epitope vaccine against this bacterium. Similarly, few immunogenic outer membrane proteins showing homology across other Vibrio spp. such as BamA/YaeT (AEH32541) could be exploited to design and develop a single therapeutic vaccine effective across Vibrio spp. However, prior to designing an epitope-based vaccine, the peptides identified need to be checked and validated for their sharing to fish MHC proteins.

In conclusion, the reverse vaccinology strategy when applied to $V$. anguillarum proteins identified 23 OMPs 
Table 3 Predicted T-cell epitopes for $V$. anguillarum outer membrane proteins and their binding probabilities to MHC class alleles

\begin{tabular}{|c|c|c|c|c|c|c|c|c|}
\hline \multirow[t]{2}{*}{ Protein accession } & \multirow[t]{2}{*}{ Protein description } & \multirow[t]{2}{*}{ Peptide sequence } & \multicolumn{2}{|c|}{$\begin{array}{l}\text { MHC class I } \\
\text { allele }\end{array}$} & \multicolumn{4}{|c|}{ MHC class II alleles } \\
\hline & & & HLA-A2 & $P$ value & HLA-DP & $P$ value & HLA-DQ & $P$ value \\
\hline \multirow[t]{4}{*}{ AEH31940 } & \multirow{4}{*}{$\begin{array}{l}\text { Ferrichrome-iron transporter } \\
\text { OMP }\end{array}$} & WLGNGTGSQVGV & + & 0.020 & - & - & + & 0.010 \\
\hline & & NAWQDSDPYTLARYTL & + & 0.010 & + & 0.030 & - & - \\
\hline & & SLNPTYGNVPDL & + & 0.010 & - & - & + & 0.020 \\
\hline & & $\underline{\text { SLAGCDFGTC }}$ & + & 0.030 & + & 0.020 & + & 0.010 \\
\hline AEH32461 & $\begin{array}{l}\text { OmpK-nucleoside-specific } \\
\text { OMP }\end{array}$ & TLMEWGGNSGVN & + & 0.002 & - & - & + & 0.009 \\
\hline \multirow[t]{8}{*}{ AEH32514 } & \multirow{8}{*}{$\begin{array}{l}\text { BamA/Yae T-outer membrane } \\
\text { assembly factor protein }\end{array}$} & LNVDVAWWNFLSDD & + & 0.020 & + & 0.038 & + & 0.082 \\
\hline & & YAYQVRTIPEFN & + & 0.022 & - & - & + & 0.012 \\
\hline & & FIGSGNRVGI & + & 0.013 & - & - & + & 0.038 \\
\hline & & GINAMMNDYQKNI & + & 0.030 & - & - & + & 0.015 \\
\hline & & KIGNINEYVQV & + & 0.035 & - & - & + & 0.001 \\
\hline & & $\underline{\text { NLNRTIFPTAG }}$ & + & 0.043 & - & - & + & 0.044 \\
\hline & & NLFPFYENYYAGG & + & 0.021 & + & 0.023 & + & 0.022 \\
\hline & & TTLRGFGSNSAGP & + & 0.038 & - & - & + & 0.006 \\
\hline \multirow[t]{3}{*}{ AEH32793 } & \multirow[t]{3}{*}{ OmpV-OMP } & DYNNYYFGV & - & - & + & 0.018 & + & 0.002 \\
\hline & & AQRKAYHAG & - & - & + & 0.010 & + & 0.003 \\
\hline & & RLSSDVANSPIVESANQW & + & 0.006 & - & - & + & 0.011 \\
\hline \multirow[t]{2}{*}{ AEH32871 } & \multirow[t]{2}{*}{ Hypothetical OMP } & $\begin{array}{l}\text { ATVAFNLDNDGVFG- } \\
\text { VDRDY }\end{array}$ & + & 0.007 & + & 0.002 & + & 0.009 \\
\hline & & GDAALSEKAQKL & + & 0.040 & - & - & + & 0.028 \\
\hline \multirow[t]{2}{*}{ AEH32884 } & \multirow[t]{2}{*}{ Hypothetical OMP } & AYYDTFTESV & + & 0.030 & + & 0.012 & - & - \\
\hline & & DGFNVFQFRGQASSIA & + & 0.030 & + & 0.061 & + & 0.019 \\
\hline \multirow[t]{3}{*}{ AEH33067 } & \multirow{3}{*}{$\begin{array}{l}\text { Periplasmic amino acid bind- } \\
\text { ing OMP }\end{array}$} & MPWSRALDEV & + & 0.035 & - & - & + & 0.025 \\
\hline & & SYLENELSFI & + & 0.016 & + & 0.046 & - & - \\
\hline & & QKYIDAYNKGL & + & 0.038 & + & 0.026 & - & - \\
\hline \multirow[t]{2}{*}{ AEH33077 } & \multirow{2}{*}{$\begin{array}{l}\text { TonB-dependent iron transport } \\
\text { OMP }\end{array}$} & PLNSVNPWNVVA & + & 0.023 & - & - & + & 0.019 \\
\hline & & ELPSATIVDI & + & 0.038 & + & 0.043 & + & 0.025 \\
\hline AEH33152 & Hypothetical OMP & - & - & - & - & - & - & - \\
\hline \multirow[t]{5}{*}{ AEH33621 } & \multirow[t]{5}{*}{ Fatty acid transport OMP } & GLSQKFQTTI & + & 0.021 & + & 0.071 & - & - \\
\hline & & TIPAGTALLNV & + & 0.008 & + & 0.011 & - & - \\
\hline & & VLPLPDIAEFSGFHKI & + & 0.037 & + & 0.020 & + & 0.094 \\
\hline & & NLDSSQSPIASILAG & + & 0.030 & - & - & + & 0.011 \\
\hline & & AGTVLTATTHADA & + & 0.028 & - & - & + & 0.019 \\
\hline AEH33622 & Fatty acid transport OMP & FSASHFGNQAMVK & + & 0.047 & - & - & + & 0.009 \\
\hline & & GSVMVKEEN & - & - & + & 0.064 & + & 0.056 \\
\hline AEH33699 & Outer membrane porin protein & VDWPHSNPGLGNVFDW & + & 0.009 & - & - & + & 0.011 \\
\hline & & NVFDWHNAIGAGYQDR & + & 0.025 & - & - & + & 0.033 \\
\hline & & DEAQAAYYL & - & - & + & 0.010 & + & 0.029 \\
\hline AEH33731 & TetR-transcriptional regulator & NEYNTNNFN & - & - & + & 0.013 & + & 0.004 \\
\hline & OMP & NITQYQNWD & - & - & + & 0.036 & + & 0.061 \\
\hline AEH34033 & OmpU-OMP & DNRYTYAGI & - & - & + & 0.040 & + & 0.013 \\
\hline & & GIGGNFGEVTYGKND & + & 0.033 & + & 0.050 & + & 0.011 \\
\hline & & GALGVITDF & - & - & + & 0.030 & + & 0.01 \\
\hline & & KAAYKIVVA & - & - & + & 0.020 & + & 0.001 \\
\hline AEH34348 & Hypothetical OMP & IEVPSPWNSQVELG & + & 0.041 & & - & + & 0.025 \\
\hline & & SSTDIVFANTVE & + & 0.022 & + & 0.002 & + & 0.032 \\
\hline & & PAGLSKADS & - & - & + & 0.036 & + & 0.028 \\
\hline AEH34505 & Hypothetical OMP & GYSFTKGRF & - & - & + & 0.026 & + & 0.031 \\
\hline
\end{tabular}


Table 3 (continued)

\begin{tabular}{|c|c|c|c|c|c|c|c|c|}
\hline \multirow[t]{2}{*}{ Protein accession } & \multirow[t]{2}{*}{ Protein description } & \multirow[t]{2}{*}{ Peptide sequence } & \multicolumn{2}{|c|}{$\begin{array}{l}\text { MHC class I } \\
\text { allele }\end{array}$} & \multicolumn{4}{|c|}{ MHC class II alleles } \\
\hline & & & HLA-A2 & $P$ value & HLA-DP & $P$ value & HLA-DQ & $P$ value \\
\hline \multirow[t]{2}{*}{ AEH34566 } & \multirow[t]{2}{*}{ TraF-conjugal transfer OMP } & LIAFGYSEFGLAL & + & 0.021 & - & - & + & 0.006 \\
\hline & & DTLDNAVTFGIGI & + & 0.044 & + & 0.012 & + & 0.017 \\
\hline \multirow[t]{7}{*}{ AEH34817 } & \multirow[t]{7}{*}{ LamB-OMP } & RLNGNSTGRL & + & 0.008 & & & & \\
\hline & & TNLNDYFWMT & + & 0.005 & + & 0.039 & - & - \\
\hline & & QGGGFYNLNLGGI & + & 0.032 & - & - & + & 0.005 \\
\hline & & GIKFDASVV & - & - & + & 0.045 & + & 0.042 \\
\hline & & DRTNYNVLV & - & - & + & 0.037 & + & 0.078 \\
\hline & & IATNSSWKVTL & + & 0.008 & - & - & + & 0.008 \\
\hline & & KDGLFKAASNPDTVTI & + & 0.040 & - & - & + & 0.034 \\
\hline \multirow[t]{4}{*}{ AEH35019 } & \multirow[t]{4}{*}{ Hypothetical OMP } & $\underline{\text { RMVDGETVDTEF }}$ & + & 0.038 & + & 0.047 & - & - \\
\hline & & AAGILSGEFWKQ & + & 0.035 & + & 0.030 & + & 0.028 \\
\hline & & DAGAATTNPERTTL & + & 0.023 & - & - & + & 0.040 \\
\hline & & SSYDLYYYGV & + & 0.037 & + & 0.004 & - & - \\
\hline \multirow[t]{3}{*}{ AEH35061 } & \multirow[t]{3}{*}{ Long-chain fatty acid OMP } & KLTRHKGALAVF & + & 0.030 & + & 0.022 & - & - \\
\hline & & NLVGMTGETVALGWN & + & 0.025 & + & 0.002 & - & - \\
\hline & & TDWSSFKEL & - & - & + & 0.080 & + & 0.021 \\
\hline \multirow[t]{2}{*}{ AEH35196 } & \multirow[t]{2}{*}{ Cyclodextrin-specific OMP } & DIRKATLGY & - & - & + & 0.030 & + & 0.040 \\
\hline & & GEYEFANEV & - & - & + & 0.003 & + & 0.003 \\
\hline
\end{tabular}

Peptide sequences binding to MHC class I alleles are underlined; + indicates binding to MHC; - indicates lack of binding capacity. Lower the $P$ value $(=0.05)$, higher the significance of binding probability

$O M P$ outer membrane protein

including two lipoproteins as vaccine candidates. While three out of these OMPs (OmpK, LamB, OmpU) have been shown to elicit a protective immune response in fish, the remaining novel antigens could be further studied in the development of a vaccine against $V$. anguillarum. Few of the antigens identified also were seen to be conserved across vibrios which could be further exploited to develop a common vaccine against vibriosis in fish. The potential B-cell and T-cell epitopes identified would help to narrow down the selection of peptides and providing a framework for future designing of an effective epitope-based vaccine against vibriosis. Our future work would focus on validating the epitopes identified in this study through in vitro and in vivo studies and its application to vaccine design. MHC molecules are highly polymorphic and exhibit allelic diversity and there are $>6000$ alleles listed for class I and II molecules for higher vertebrates in IMGT/HLA database $[32,37]$. However, in fish there is a paucity of data concerning MHC proteins and their allelic diversity. Hence, there is also a need for basic research on MHC proteins in fish of interest.

Acknowledgements The financial support from the Department of Biotechnology, Government of India, under the Bioinformatics Centre programme is gratefully acknowledged.

\section{References}

1. Ariel N, Zvi A, Grosfeld H, Gat O, Inbar Y, Velan B, Cohen S, Shafferman A (2002) Search for potential vaccine candidate open reading frames in the Bacillus anthracis virulence plasmid $\mathrm{pXO1}$ : in silico and in vitro screening. Infect Immun 70(12):6817-6827

2. Austin B, Austin A (2007) Bacterial fish pathogens. In: Diseases of farmed and wild fish, vol 4. Springer-Praxis Publishing, Chichester, $\mathrm{p} 411$

3. Bagos PG, Liakopoulos TD, Spyropoulos IC, Hamodrakas S (2004) PRED-TMBB: a web server for predicting the topology of $\beta$-barrel outer membrane proteins. Nucleic Acids Res 32:W400 W404. https://doi.org/10.1093/nar/gkh417

4. Betts JC (2002) Transcriptomics and proteomics: tools for the identification of novel drug targets and vaccine candidates for tuberculosis. IUBMB Life 53(4-5):239-242. https://doi. org/10.1080/15216540212651

5. Buchanan SK (1999) Beta-barrel proteins from bacterial outer membranes: structure, function and refolding. Curr Opin Struc Biol 9:455-461

6. Chen J, Liu H, Yang J, Chou KC (2007) Prediction of linear B-cell epitopes using amino acid pair antigenicity scale. Amino Acids 33(3):423-428

7. Chiang MH, Sung WC, Lien SP, Chen YZ, Lo AF, Huang JH, Chong P (2015) Identification of novel vaccine candidates against Acinetobacter baumannii using reverse vaccinology. Hum Vaccin Immunother 11(4):1065-1073. https://doi.org/10.1080/21645515 .2015 .1010910

8. Chung JW, Ng-Thow-Hing C, Budman LI, Gibbs BF, Nash JHE, Jacques M, Coulton JW (2007) Outer membrane proteome of 
Actinobacillus pleuropneumoniae: LC-MS/MS analyses validate in silico predictions. Proteomics 7:1854-1865. https://doi. org/10.1002/pmic.200600979

9. Dash, Ramachandran S, Brahmachari KS (2005) GenoCluster: a novel platform for comparative genomics. http://genocluster. indiancst.in

10. Doytchinova IA, Flower DR (2007) VaxiJen: a server for prediction of protective antigens, tumour antigens and subunit vaccines. BMC Bioinform 8:4. https://doi.org/10.1186/1471-2105-8-4

11. El-Manzalawy Y, Dobbs D, Honavar V (2008) Predicting linear B-cell epitopes using string kernels. J Mol Recog 21(4):243-255

12. El-Manzalawy Y, Dobbs D, Honavar V (2008) Predicting flexible length linear B-cell epitopes. Comput Syst Bioinform Conf 7:121-132

13. Feng J, Lin P, Guo S, Jia Y, Wang Y, Zadlock F, Zhang Z (2017) Identification and characterization of a novel conserved $46 \mathrm{kD}$ maltoporin of Aeromonas hydrophila as a versatile vaccine candidate in European eel (Anguilla anguilla). Fish Shellfish Immunol 64:93-103. https://doi.org/10.1016/j.fsi.2017.03.010

14. Frans I, Michiels CW, Bossier P, Willems KA, Lievens B, Rediers $\mathrm{H}$ (2011) Vibrio anguillarum as a fish pathogen: virulence factors, diagnosis and prevention. J Fish Dis 34:643-661. https://doi. org/10.1111/j.1365-2761.2011.01279.x

15. Grimholt U (2016) MHC and evolution in teleosts. Biology 5(1):6. https://doi.org/10.3390/biology5010006

16. Hamod MA, Nithin MS, Shukur YN, Karunasagar I, Karunasagar I (2012) Outer membrane protein $\mathrm{K}$ as a subunit vaccine against $V$. anguillarum. Aquaculture 354-355:107-110. https:// doi.org/10.1016/j.aquaculture.2012.03.033

17. He Y, Xiang Z, Mobley HL (2010) Vaxign: the first web-based vaccine design program for reverse vaccinology and applications for vaccine development. J Biomed Biotechnol. https://doi. org/10.1155/2010/297505

18. Hughes E, Gilleland HJ (1995) Ability of synthetic peptides representing epitopes of outer membrane protein F of Pseudomonas aeruginosa to afford protection against $P$. aeruginosa infection in a murine acute pneumonia model. Vaccine 13(18):1750-1753

19. Jaiswal V, Chanumolu SK, Gupta A, Chauhan RS, Rout C (2013) Jenner-predict server: prediction of protein vaccine candidates (PVCs) in bacteria based on host-pathogen interactions. BMC Bioinform 14:211. https://doi.org/10.1186/1471-2105-14-211

20. Juncker AS, Willenbrock H, Heijne VG, Brunak S, Nielsen H, Krogh A (2003) Prediction of lipoprotein signal peptides in Gram-negative bacteria. Protein Sci 12(8):1652-1662. https:// doi.org/10.1110/ps.0303703

21. Khushiramani R, Maiti B, Shekar M, Girisha SK, Akash N, Deepanjali A, Karunasagar I, Karunasagar I, (2012) Recombinant Aeromonas hydrophila outer membrane protein 48 (omp48) induces protective immune response against Aeromonas hydrophila and Edwardsiella tarda. Res Microbiol 163: 286-291. https://doi. org/10.1016/j.resmic.2012.03.001

22. Koebnik R, Locher KP, Gelder PV (2000) Structure and function of bacterial outer membrane proteins: barrels in a nutshell. Mol Microbiol 37:239-253

23. Kolaskar AS, Tongaonkar PC (1990) A semi-empirical method for prediction of antigenic determinants on protein antigens. FEBS Lett 276(1-2):172-174

24. Lightner DV (1996) A handbook of shrimp pathology and diagnostic procedures for diseases of cultured penaeid shrimp. World Aquaculture Society, Baton Rough

25. Lun J, Xia C, Yuan C, Zhang Y, Zhong M, Huang T, Hu Z (2014) The outer membrane protein, LamB (maltoporin), is a versatile vaccine candidate among the Vibrio species. Vaccine 32:809-815. https://doi.org/10.1016/j.vaccine.2013.12.035

26. Maiti B, Shetty M, Shekar M, Karunasagar I, Karunasagar I (2011) Recombinant outer membrane protein (OmpA) of
Edwardsiella tarda, a potential vaccine candidate for fish, common carp. Microbiol Res 167:1-7. https://doi.org/10.1016/j. micres.2011.02.002

27. Manque PA, Tenjo F, Woehlbier U, Lara AM, Serrano MG, Xu P, Alves JM, Smeltz RB, Conrad DH, Buck GA (2011) Identification and immunological characterization of three potential vaccinogens against Cryptosporidium. Clin Vaccine Immunol 18(11):17961802. https://doi.org/10.1128/CVI.05197-11

28. Meunier M, Guyard-Nicodème M, Hirchaud E, Parra A, Chemaly M, Dory D (2016) Identification of novel vaccine candidates against Campylobacter through reverse vaccinology. J Immunol Res 5715790:9. https://doi.org/10.1155/2016/5715790

29. Myhr E, Larsen JL, Lillehaug A, Gudding R, Heum M, Hastein T (1991) Characterization of Vibrio anguillarum and closely related species isolated from farmed fish in Norway. Appl Environ Microbiol 57:2750-2757

30. Park YH, Hwang SY, Hong MK, Kwon KH (2012) Use of antimicrobial agents in aquaculture. Rev Sci Technol 31(1):189-197

31. Parker JM, Guo D, Hodges RS (1986) New hydrophilicity scale derived from high-performance liquid chromatography peptide retention data: correlation of predicted surface residues with antigenicity and X-ray-derived accessible sites. BioChemistry 25(19):5425-5432

32. Patronov A, Doytchinova I (2013) T-cell epitope vaccine design by immunoinformatics. Open Biol 3:120139. https://doi.org/10.1098/ rsob.120139

33. Petersen TN, Brunak S, Heijne VG, Nielsen H (2011) SignalP 4.0: discriminating signal peptides from transmembrane regions. Nat Methods 8:785-786. https://doi.org/10.1038/nmeth.1701

34. Pizza M, Scarlato V, Masignani V, Giuliani MM, Arico B, Comanducci M, Jennings GT, Baldi L, Bartolini E, Capecchi $B$ et al (2000) Identification of vaccine candidates against serogroup $B$ meningococcus by whole-genome sequencing. Science 287(5459):1816-1820

35. Rahman MH, Kawai K (2000) Outer membrane proteins of Aeromonas hydrophila induce protective immunity in goldfish. Fish Shellfish Immunol 10:379-382

36. Rappuoli R (2000) Reverse vaccinology. Curr Opin Microbiol 3(5):445-450

37. Robinson J, Mistry K, McWilliam H, Lopez R, Parham P, Marsh SGE (2011) The IMGT/HLA database. Nucleic Acids Res 39:D1171-D1176. https://doi.org/10.1093/nar/gkq998

38. Sambrook JG, Figueroa F, Beck S (2005) A genome-wide survey of major histocompatibility complex (MHC) genes and their paralogues in zebrafish. BMC Genom 6:152. https://doi. org/10.1186/1471-2164-6-152

39. Sharma M, Dixit A (2016) Immune response characterization and vaccine potential of a recombinant chimera comprising B-cell epitope of Aeromonas hydrophila outer membrane protein C and LTB. Vaccine 34:6259-6266. https://doi.org/10.1016/j. vaccine.2016.10.064

40. Silhavy TJ, Kahne D, Walker S (2010) The bacterial cell envelope. Cold Spring Harb Perspect Biol 2(5):a000414. https://doi. org/10.1101/cshperspect.a000414

41. Sommerset I, Krossøy B, Biering E, Frost P (2005) Vaccines for fish in aquaculture. Expert Rev Vaccines 4(1):89-101. https://doi. org/10.1586/14760584.4.1.89

42. Stothard P (2000) The sequence manipulation suite: JavaScript programs for analyzing and formatting protein and DNA sequences. Biotechniques 28:1102-1104

43. Tang X, Zhan W, Sheng X, Chi H (2010) Immune response of Japanese flounder Paralichthys olivaceus to outer membrane proteins of Edwardsiella tarda. Fish Shellfish Immunol 28:333-343. https://doi.org/10.1016/j.fsi.2009.11.015

44. Wang SY, Lauritz J, Jass J, Milton DL (2003) Role for the major outer-membrane protein from Vibrio anguillarum in bile 
resistance and biofilm formation. Microbiology 149(4):10611071. https://doi.org/10.1099/mic.0.26032-0

45. Wizemann TM, Heinrichs JH, Adamou JE, Erwin AL, Kunsch C, Choi GH, Barash SC, Rosen CA, Masure HR, Tuomanen E et al (2001) Use of a whole genome approach to identify vaccine molecules affording protection against Streptococcus pneumoniae infection. Infect Immun 69(3):1593-1598. https://doi.org/10.1128/ IAI.69.3.1593-1598.2001

46. Xiang Z, He Y (2013) Genome-wide prediction of vaccine targets for human herpes simplex viruses using
Vaxign reverse vaccinology. BMC Bioinform 14(4):S2. https:// doi.org/10.1186/1471-2105-14-S4-S2

47. Yu NY, Wagner JR, Laird MR, Melli G, Rey S, Lo R, Dao P, Sahinalp SC, Ester M, Foster LJ, Brinkman FSL (2010) PSORTb 3.0: Improved protein subcellular localization prediction with refined localization subcategories and predictive capabilities for all prokaryotes. Bioinformatics 26(13):1608-1615. https://doi. org/10.1093/bioinformatics/btq249 